\title{
ISOTOPIA TEXTUAL E O MEIO PUBLICITÁRIO: OS CAMINHOS PARA A GERAÇÃO DE SENTIDO
}

\author{
Alcione Alves Farias ${ }^{1}$ \\ Andréia Costa Mouzinho ${ }^{2}$ \\ Brenda Melo das Neves ${ }^{3}$ \\ Welton Diego Carmin Lavareda ${ }^{4}$
}

\begin{abstract}
Resumo
Tomando como base a perspectiva da Semiótica Discursiva, fundada por Algirdas Julien Greimas, o presente trabalho tem como objetivo analisar as estratégias textuais isotópicas utilizadas em um comercial da Rede Americana de Fast Food Burger King como artifício para o alcance de um determinado público-alvo. Sob esse prisma teórico, faz-se necessário um diálogo metodológico baseado em Barros (2005), Fiorin (1999) e Henn (2006), dentre outros autores que discorrem sobre as temáticas concernentes a esse campo de estudo. Uma peça publicitária produzida pela Burger King comporá o corpus e será tomada como objeto de significação e cultural, de interação entre os sujeitos, evidenciando possíveis relações ideológicas entre interlocutores.

Palavras-chave: Semiótica Discursiva. Isotopia Textual. Memória de Enquadramento.

\section{ISOTOPIA TEXTUAL AND THE ADVERTISING MEDIUM: THE PATHS FOR THE GENERATION OF MEANING}

\begin{abstract}
Based on the perspective of Discursive Semiotics, developed by Algirdas Julien Greimas, this work aims to analyze the isotopic textual strategies used in a commercial of the American Fast Food Burger King Network as a trick to reach a certain target audience. From this theoretical perspective, a methodological dialogue based on Barros (2005), Fiorin (1999) and Henn (2006), among other authors who discuss topics related to this field of study, is necessary. An

\footnotetext{
${ }^{1}$ Centro Universitário Fibra. Especialista em Redação e Revisão Textual em Língua Portuguesa pelo Centro Universitário FIBRA. Graduada no curso de Letras - Língua Portuguesa pela Universidade Federal do Pará (2018). Graduanda do curso de Letras - Língua Espanhola da Universidade Federal do Pará. ORCID $<$ http://orcid.org/0000-0002-4047-2630>. E-mail: alcifaria82@gmail.com

${ }^{2}$ Centro Universitário Fibra. Especialista em Redação e Revisão Textual pelo Centro Universitário FIBRA (2020). Graduada em Licenciatura Plena em Letras - Língua Portuguesa pela Universidade do Estado do Pará UEPA (2018). Professora de Língua Portuguesa e Redação na rede privada de ensino. É integrante do Grupo de Pesquisa Estudos Linguísticos e Práticas Educacionais da Amazônia - GELPEA/UEPA/UFPA. ORCID $<$ http://orcid.org/0000-0002-2077-1107>. E-mail: andreiamouzinho@gmail.com

${ }^{3}$ Centro Universitário Fibra. Especialista em Redação e Revisão Textual em Língua Portuguesa pelo Centro Universitário FIBRA. Licenciada plena em Letras com habilitação em Língua Portuguesa pela Universidade do Estado do Pará - UEPA. É professora de Língua Portuguesa, Literatura e Redação do Ensino Fundamental e Médio na rede privada de ensino. ORCID $<$ http://orcid.org/0000-0003-4006-6349>. E-mail: brendamelo0910@gmail.com

${ }^{4}$ Universidade Federal do Pará e Universidade da Amazônia. Doutorando em Estudos Linguísticos (Área de Concentração: Análise do Discurso) pela Universidade Federal do Pará (PPGL/UFPA). É professor da Universidade da Amazônia (UNAMA), lotado no Centro de Ciências Humanas e Sociais, e do Centro Universitário Fibra, onde colabora na Graduação em Letras e na Pós-Graduação Lato Sensu em Letras. ORCID $<$ http://orcid.org/0000-0002-6260-3558>. E-mail: diego.lavareda@hotmail.com
} 


\section{Linguagens - Revista de Letras, Artes e Comunicação - ISSN 1981- 9943 \\ Blumenau, v. 14, n. 2, p. 143-163, maio/ago. 2020. \\ DOI: http://dx.doi.org/10.7867/1981-9943.2020v14n2p143-163}

advertising piece produced by Burger King will be used, which will compose the corpus and be taken as an object of meaning and cultural object of interaction between the subjects, highlighting possible ideological relations between interlocutors.

Keywords: Discursive Semiotics. Textual Isotopy. Framing Memory.

\section{PRIMEIRAS PALAVRAS}

Nos estudos da linguagem, muitas foram as propostas em torno do que seria a unidade linguística por excelência capaz de transmitir significação. Dessas abordagens, algumas defendiam ser a frase a unidade linguística dotada de sentido máximo, outras reconheciam o texto, por este ser um todo de sentido e manter relações entre enunciador e enunciatário. Tal abordagem diz respeito ao campo de estudo denominado Semiótica Discursiva (Semiótica Greimasiana ou Semiótica Francesa) o qual tem como base as referências teóricas e epistemológicas de seu fundador, Algirdas Julien Greimas, que concebe o texto como o objeto de estudo que busca "[...] descrever e explicar o que o texto diz e como ele faz para dizer o que diz.” (BARROS, 2005, p. 7).

Sob esse aspecto, para a Semiótica greimasiana, o texto é definido pelos mecanismos e elementos que o estruturam, fazendo-o um todo de sentido, e pelas relações estabelecidas entre os objetos culturais - situados numa sociedade organizada em classes - e determinado por formações ideológicas determinadas conforme expôs Barros (2005, p. 12).

Considerado como objeto de significação e interação, o texto, para a semiótica colocada em perspectiva, pode ser verbal, não-verbal ou sincrético ${ }^{5}$ - quando expressado por mais de uma linguagem - como é o caso daqueles que circulam no ambiente publicitário, o qual nem sempre tem como finalidade vender algo, muitas vezes, o intuito é promover ideias, são as chamadas publicidades sociais "esse tipo de publicidade (de cunho social) pode estar focada no problema da fome, na defesa das minorias, na denúncia de violência, nas questões ambientais e do futuro do planeta, entre tantos outros temas." (CRESTANI; CAYSER; SANTOS, 2019, p. 294).

Em contrapartida, muitas dessas publicidades fazem uso de várias linguagens que, diversas vezes, possibilitam mais de uma significação por parte do leitor. Tal significação é possibilitada tendo em vista a presença de temas (noções valorativas) e figuras (termos que

\footnotetext{
${ }^{5}$ O texto para a Semiótica Discursiva pode ser linguístico, indiferentemente oral ou escrito - uma poesia, um romance, um editorial de jornal, uma oração, um discurso político, um sermão, uma aula, uma conversa de crianças — quanto um texto visual ou gestual — uma aquarela, uma gravura, uma dança — ou, mais frequentemente, um texto sincrético de mais de uma expressão - uma história em quadrinhos, um filme, uma canção popular. (BARROS, 2005, p. 12).
} 


\section{Linguagens - Revista de Letras, Artes e Comunicação - ISSN 1981- 9943 \\ Blumenau, v. 14, n. 2, p. 143-163, maio/ago. 2020. \\ DOI: http://dx.doi.org/10.7867/1981-9943.2020v14n2p143-163}

remetem ao mundo real) que contribuem para a concretização do sentido por produzirem percursos de leitura se reiterando na construção da unidade, é o que chamamos de isotopia a qual diz respeito a "[...] reiteração dos temas e a recorrência das figuras no discurso que asseguram a coerência textual" (BARROS, 2005, p. 71). Ou seja, o meio publicitário lança mão de vários artifícios textuais para alcançar um objetivo desejado e, sobretudo, um público específico.

Posto dessa forma, para o presente trabalho, traçou-se, como objetivo geral, analisar as estratégias textuais isotópicas utilizadas pela Rede Americana de Fast Food Burger King como artifício para o alcance de um determinado público-alvo e, como objetivos específicos, pretende-se selecionar uma propaganda como materialidade discursiva que produz, estrategicamente, efeitos de sentidos múltiplos, ou seja, várias interpretações; observar os modos de articulação, na publicidade, entre temas e figuras que evidenciam determinados universos semânticos e, por fim, identificar os mecanismos de ordem verbal e visual que se inter-relacionam, na propaganda, a fim de enunciar um discurso persuasivo.

Assim sendo, na busca de sistematizar a pesquisa, o estudo em questão está dividido em dois momentos: no primeiro, buscou-se discutir as questões teóricas, as quais atuam como suporte teórico-metodológico necessário para a compreensão de algumas das concepções a respeito da Semiótica Discursiva, destacando-se os estudos realizados por Barros (2005), Fiorin (1999), Henn (2006), entre outros. E, no segundo momento, a pesquisa se detém sobre a análise da materialidade escolhida, a propaganda veiculada pela Burger King, que evidencia as relações ideológicas entre enunciador e enunciatário por meio de um discurso persuasivo, de cunho social e político, o qual reflete o posicionamento dessa rede de alimentação perante à sociedade, eis por isso a escolha desse corpus.

\section{DIÁLOGO TEÓRICO-METODOLÓGICO}

Por ser uma pesquisa fundamentada nas teorias da semiótica greimasiana, nesta seção, abordamos, de forma mais detalhada, as reflexões conceituais acerca dessa área de estudo para situar o leitor e fazê-lo compreender o caminho aqui traçado para o alcance dos objetivos elencados e, sobretudo, observar como foram realizadas as articulações dessas teorias na análise do corpus.

2.1 A SEMIÓTICA DISCURSIVA: O TEXTO COMO ELEMENTO PRINCIPAL DE ANÁLISE 


\section{Linguagens - Revista de Letras, Artes e Comunicação - ISSN 1981- 9943 \\ Blumenau, v. 14, n. 2, p. 143-163, maio/ago. 2020. \\ DOI: http://dx.doi.org/10.7867/1981-9943.2020v14n2p143-163}

Em se tratando de Semiótica Francesa, podemos indicar, predominantemente, duas instâncias na análise de um texto, isto é, um modelo interpretativo (não necessariamente uma regra) que permite verificar como é constituído especificamente o sentido desse objeto a partir do uso de determinados mecanismos interpretativos. Tal modelo de análise diz respeito ao plano de expressão e ao plano de conteúdo os quais sintetizam efetivamente o objeto semiótico, evidenciando os efeitos de sentido apreendidos intuitivamente pelo enunciatário. Esses planos são produzidos, segundo Souza Filho (2008, p. 26), num “[...] discurso - a unidade de sentido do plano de conteúdo - no qual as formas abstratas são revestidas de elementos concretos, cuja manifestação por um plano de expressão dá origem ao texto", sendo elas também responsáveis pela coesão e coerência textual.

Para apreender o sentido do objeto, portanto, a semiótica abstraiu, num primeiro momento, o plano de expressão para examinar o plano de conteúdo. Essa metodologia de análise do plano de conteúdo denominado Percurso Gerativo de Sentido (doravante PGS) é constituído por três níveis ou etapas, são elas: nível fundamental, o narrativo e o discursivo; e propõe fazer uma análise que "[...] vai do mais simples e abstrato ao mais complexo e concreto" (FIORIN, 1999, p. 03), responsável por conduzir o leitor à compreensão do texto possibilitando uma previsibilidade dos sentidos apreendidos.

Cada um desses níveis do PGS é composto por uma organização semântica e uma sintática próprias. O primeiro nível, chamado fundamental, é onde há a interpretação mais ampla, simples e abstrata de um texto, cuja semântica está ligada à oposição entre dois termos de uma mesma categoria de significação, por exemplo, morte, vida; frio, quente. Essa relação de contrariedade é representada por um modelo denominado 'Quadrado Semiótico'6. Assim, esse nível abriga as categorias de análise que compõem a base da construção de um texto. Veja a Figura 1:

\footnotetext{
${ }^{6}$ Modelo lógico de representação da estrutura elementar, que a torna operatória. No quadrado representa-se a relação de contrariedade ou de oposição entre os termos e, a partir dela, as relações de contradição e de complementaridade (BARROS, 2005, p. 84-85).
} 


\section{Linguagens - Revista de Letras, Artes e Comunicação - ISSN 1981- 9943 \\ Blumenau, v. 14, n. 2, p. 143-163, maio/ago. 2020. \\ DOI: http://dx.doi.org/10.7867/1981-9943.2020v14n2p143-163}

Figura 1 - Categorias de Análise do Nível Fundamental

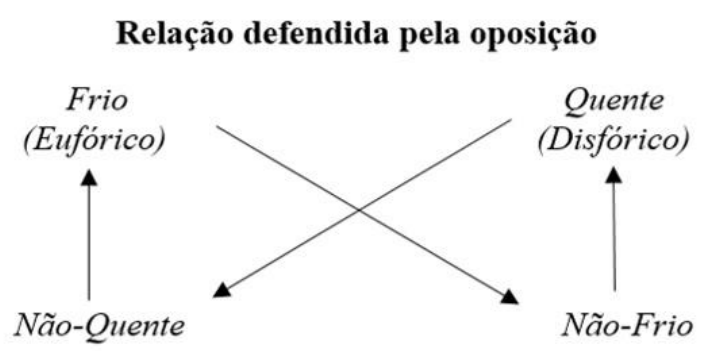

\begin{tabular}{lll} 
& \multicolumn{3}{c}{ Negação contrária } \\
Quente ---------- Não quente ------------ Frio \\
(Disforia) & (Não-disforia) & (Euforia) \\
& & \\
Frio------------Não frio-----------Quente \\
(Euforia) & (Não-euforia) & (Disforia)
\end{tabular}

Fonte: Autoria nossa

O segundo nível do modelo interpretativo do plano de conteúdo é o narrativo. Essa etapa, segundo Barros (2005 p. 20), “[...] deve ser pensada como um espetáculo que simula o fazer do homem que transforma o mundo" e, para isso, faz-se necessário descrever esse espetáculo determinando os participantes e o papel que representam na narrativa. Em suma, esse nível é o das transformações e mudanças de estado do(s) sujeito(s) e da(s) coisa(s); de rupturas nos contratos estabelecidos entre um sujeito destinador e destinatário. Ainda nesse nível, há relações diretas e transitivas entre sujeito e objeto. Tais relações dizem respeito aos enunciados que podem ser de junção e transformação responsáveis por determinar, no texto, a distinção entre estado e fazer, respectivamente.

Nos enunciados de estado, são estabelecidas as relações de junção entre sujeito e objeto que podem ser de dois tipos: conjunção e disjunção; podendo o sujeito afirmá-los ou negá-los, enquanto que nos enunciados de fazer, tem-se as transformações do sujeito. Essas relações de enunciados de estado e de fazer são hierárquicas e se organizam em quatro fases: manipulação, competência, performance e sanção; bem como definem uma "[...] unidade elementar na organização narrativa de um texto" (BARROS, 2005, p. 23), isto é, um programa narrativo o qual estabelece dois tipos fundamentais de programas: o de competência e o de performance.

Na sistematização desse nível, o sujeito assume a narração e simula a história e, na primeira fase - manipulação -, ele manipula outro sujeito para realizar uma determinada ação. Essa manipulação pode ser de vários modos e pode se dar por meio de quatro grandes figuras: tentação, intimidação, provocação e sedução. Na segunda fase, tem-se a competência, “[...] um tipo de programa narrativo, em que o destinatário-sujeito recebe do destinador a qualificação necessária à ação" (BARROS, 2005, p. 80), em outras palavras, o sujeito se deixa manipular, quer e pode realizar a ação e, para que isso ocorra, é necessário que haja uma certa relação de cumplicidade entre os interlocutores.

A terceira fase se refere à performance, "[...] é o programa narrativo que representa a ação do sujeito que se apropria, por sua própria conta, dos objetos-valor que deseja" (BARROS, 


\section{Linguagens - Revista de Letras, Artes e Comunicação - ISSN 1981- 9943 \\ Blumenau, v. 14, n. 2, p. 143-163, maio/ago. 2020. \\ DOI: http://dx.doi.org/10.7867/1981-9943.2020v14n2p143-163}

2005, p. 84), isto é, depois que o sujeito aceita a manipulação, adquire a competência necessária e realiza a ação exigida pelo manipulador.

Por fim, há a sanção, “[...] última fase da organização narrativa, necessária para encerrar o percurso do sujeito e correlata à manipulação. Organiza-se pelo encadeamento lógico de programas narrativos de dois tipos: o de sanção cognitiva ou interpretação e o de sanção pragmática ou retribuição" (BARROS, 2005, p. 35). Corresponde à recompensa que o sujeito manipulado recebe pela realização da ação exigida pelo manipulador, pode ser de natureza positiva ou negativa, a qual só é definida quando o "[...] destinador interpreta as ações do destinatário-sujeito, julga-o, segundo certos valores, e dá-lhe a retribuição devida, sob a forma de punições ou de recompensas" (BARROS, 2005, p. 85), ou seja, quem define a sanção recompensa - é o manipulador.

Já o terceiro nível do PGS, chamado discursivo, é o mais próximo da manifestação textual real. É nele que as escolhas temáticas e figurativas adquirem a concretude que reveste as categorias abstratas dos níveis anteriores que são assumidos pelos sujeitos da enunciação, assim, o sentido de um texto depende do encadeamento desses níveis. A sintaxe desse nível analisa as relações entre enunciador-enunciado e enunciador-enunciatário, já a semântica é responsável por converter os percursos narrativos em percursos temáticos que são recobertos por figuras. "Assim, no discurso, as figuras constituem a representação do mundo real ou fictício. Já os temas são elementos que organizam, classificam, ordenam a realidade.” (LORENZ, 2013, p. 03).

A semântica desse nível, de acordo com Fiorin (1999), apresenta dois procedimentos: a tematização e a figurativização. Os primeiros são compostos predominantemente de temas, isto é, de termos abstratos; os segundos, preponderantemente de figuras, ou seja, de termos concretos. Ao analisar a coerência semântica com base nos procedimentos citados, devemos ter em mente que:

\footnotetext{
Para se interpretar um texto que utilize figuras no nível discursivo, é necessário descobrir o tema que se encontra recoberto pelas figuras. No entanto, não se pode considerar uma figura ou um tema isolado, é necessário analisar os encadeamentos das figuras ou dos temas. Ao encadeamento de figuras dá-se o nome de percurso figurativo e ao de temas, percurso temático. Tanto um quanto o outro necessita manter uma coerência interna, sob pena de tornarem o discurso inverossímil ou contraditório. Por outro lado, a quebra proposital da coerência pode ser um recurso para criar determinados efeitos de sentido (LORENZ, 2013, p. 03, grifo nosso).
}

Essa reiteração dos elementos temáticos e figurativos que constituem um plano de leitura recebe o nome de isotopia. É importante ressaltar que toda construção textual permite múltiplas leituras, porém possui apenas um percurso interpretativo invariável a ser seguido por 
todos os sujeitos, caso contrário, seu sentido global pode ser comprometido. Cabe ressaltar também que, em relação ao PGS, um texto pode trabalhar melhor um nível do que outro, mais um componente do que outro e, por conta disso, faz-se necessário um direcionamento do olhar no momento da análise, para que seja dada a devida ênfase ao(s) aspecto(s) mais explorado(s) na materialidade textual em questão.

\subsection{A ISOTOPIA E A CONSTRUÇÃO DO SENTIDO DO TEXTO}

Viu-se anteriormente que, ao tomar o texto como objeto de significação, a semiótica se preocupa em estudar os mecanismos que o integram como um todo significativo. Portanto, ao observarmos todos os níveis que abarcam o PGS, podemos perceber no texto, seja ele verbal, não-verbal ou sincrético, a presença de um plano de leitura que favorece a compreensão textual por meio da relação entre o encadeamento desses níveis.

No entanto, é na última etapa desse modelo interpretativo - o nível discursivo - que se verificam os temas (termos abstratos que explicam uma dada realidade) e as figuras (termos concretos que criam simulacros do mundo) os quais são responsáveis, respectivamente, pela coerência semântica e por atribuírem efeitos de sentido de realidade a esse texto. Em outras palavras, é no nível discursivo de análise que os temas e as figuras se reiteram e proporcionam a isotopia.

Termo que migrou da físico-química, isotopia significa um “[...] fenômeno apresentado por vários nuclídeos que têm o mesmo número atômico, mas números de massa diferentes" (HOLANDA, 1986, p. 973). Ao ingressar no campo dos estudos semióticos, esse termo passou a denominar os elementos concatenados por uma mesma concepção, permitindo coerência e ordenando os pensamentos posteriores.

\footnotetext{
A.J. Greimas tomou ao domínio da físico-química o termo isotopia e o transferiu para a análise semântica, conferindo-lhe uma significação específica, levando em consideração seu novo campo de aplicação. De caráter operatório, o conceito de isotopia designou inicialmente iteratividade, no decorrer de uma cadeia sintagmática, de classemas que garantem ao discurso-enunciado a homogeneidade. (GREIMAS; COURTÉS, 1979, p. 245)
}

Com isso, a isotopia se apresenta como um agente determinante para a interpretação textual que atribui ao leitor uma dada leitura ou planos de leitura, haja vista que um texto pode ter mais de uma isotopia, e isso contribui para revelar práticas socioculturais mergulhadas em tematização e figurativização, bem como reafirma o próprio objetivo dos estudos semióticos de descrever e explicar como o texto diz e/ou enuncia um determinado discurso. 
Ainda no que diz respeito ao conceito de isotopia, Leite (2014), afirma ser a ocorrência sincrônica de dois planos significativos durante a interpretação que torna a leitura do texto homogênea e coerente, ou seja, essa manifestação pode ser representada por um domínio conceitual com características semânticas distintas ou semelhantes em certos aspectos, que se estabelece por meio de uma tensão semântica, que pode ser lida de dois modos mediante o dualismo isotópico, causando a pluralidade na leitura do texto. À vista disso, a isotopia permitenos encontrar no texto elementos concretos pertencentes ao mundo real e elementos temáticos que pertencem, segundo o autor, ao mundo natural "um texto cujo tema 'fuga da prisão', foi construído a partir das seguintes figuras: muro, grade, corda, homem, noite.” (LEITE, 2009, p. 126-127).

Diante dessas colocações, o que se torna indiscutível é o fato de que tanto os temas como as figuras são imprescindíveis para tornar o discurso "verídico" e persuasivo, haja vista que constroem uma significação global sobre o texto,

a coerência semântica do texto/discurso é função tanto de isotopias figurativas quanto de isotopias temáticas: enquanto a isotopia figurativa atribui ao texto/discurso uma imagem organizada e completa da realidade, ou uma ilusão total do irreal, através da redundância de traços figurativos, a isotopia temática revela sua dimensão abstrata. (LEITE, 2009, p. 127-128).

Com isso, percebe-se a importância que os estudos semióticos - com o conceito de isotopia particularmente - trouxeram para a linguagem, reafirmando que o texto não é um simples amontoado de temas e figuras aleatórias, mas uma unidade significativa que possibilita inúmeras interpretações.

\subsection{O PROCESSO DE DESAMBIGUAÇÃO TEXTUAL E O ENQUADRAMENTO DO OLHAR}

Para que um texto, provido de palavras com múltiplos significados, possa ser depreendido, faz-se necessário desfazer sua ambiguidade, em outras palavras, deve-se provê-lo sob o processo de desambiguação cuja a intenção seja de definir o real significado da expressão que está inserida em um determinado contexto, visto que é impossível compreender um termo se não há convicção do significado que este apresenta num contexto específico (RIESS; GABRIEL, 2019).

À vista disso, encontra-se a desambiguação lexical, “[...] campo da ciência que surgiu motivado pela área de Tradução Automática, visto a necessidade de determinar o sentido da 


\title{
Linguagens - Revista de Letras, Artes e Comunicação - ISSN 1981- 9943 \\ Blumenau, v. 14, n. 2, p. 143-163, maio/ago. 2020. \\ DOI: http://dx.doi.org/10.7867/1981-9943.2020v14n2p143-163
}

palavra para, posteriormente, traduzi-la" (NÓBREGA, 2013, p. 02) que tem como objetivo desenvolver métodos para determinar o significado mais adequado de uma expressão em um contexto determinado. No entanto, para isso faz-se necessário compreender, segundo Riess e Gabriel (2019), que para termos ambiguidade deve haver o fenômeno da polissemia e da homonímia,

\begin{abstract}
A polissemia tem como característica a existência de múltiplos significados para uma única palavra; já as palavras homônimas são aquelas que também carregam vários significados, entretanto, têm origem diferente, tendo convergido foneticamente. Um exemplo de polissemia é a palavra "cabo", como em "O cabo quebrou e não conseguimos terminar o trabalho" que tanto pode remeter ao significado cabo de vassoura, como ao cabo de equipamentos elétricos. Já na homonímia, o campo semântico das palavras é muito distante, tal como em "manga" referindo-se à fruta ou à parte da camisa. A palavra "cabo" também pode ser homônima, se utilizada no sentido de oficial militar, bastante distante de cabo elétrico. (RIESS; GABRIEL, 2019, p. 183).
\end{abstract}

É interessante, aliás, afirmar que a função de desambiguação na acepção das palavras constitui-se em esclarecer o dilema da ambiguidade concebida no nível lexical. Torna-se necessário, então, “[...] demarcar todos os fenômenos observados dentro de um encadeamento vocabular para que, por fim, seja definida apropriadamente a tarefa de desambiguação" (SILVA, 2016). De acordo com essa perspectiva, o interesse em incluir o fenômeno de desambiguação na investigação de termos isotópicos e suas relações é o de contribuir com as análises linguísticas voltadas para os estudos da isotopia textual, que particularmente são encontrados em diferentes planos de leitura, bem como perceber a capacidade do interlocutor em desambiguar o léxico durante a leitura por meio de inferências textuais e intertextuais, decidindo os sentidos das palavras no contexto.

Essa possibilidade de desambiguação para obter os sentidos das palavras num contexto específico advém das relações que os indivíduos estabelecem com o sistema social e, sobretudo, da estruturação de uma dada materialidade discursiva a qual, por meio de uma dinâmica de enquadramento do olhar, conflui para uma memória coletiva midiatizada promovida efetivamente, segundo Henn (2006), pela produção jornalística. Esse dispositivo midiático é, senão, o maior armazenador de informações e dinâmicas sociais que, muitas vezes, as transforma em fontes historiográficas por meio de “[...] um discurso organizado em torno de acontecimentos e de personagens célebres que formam, ao longo do tempo, o enquadramento da memória que se solidifica em grandes monumentos" (HENN, 2006, p. 227).

Sendo assim, é importante refletir como as imagens são consumidas no contexto da contemporaneidade, afinal, Pollak (1989) salienta que não se trata mais de lidar com os fatos sociais como coisas, mas de lidar como os fatos sociais se tornam coisas que são dotadas de 
duração e estabilidade, mas só acontece esse processo porque esse enquadramento é promovido por dois fatores: pela produção jornalística e pela produção publicitária, pois os sujeitos elaboram seus conhecimentos acerca do mundo a partir do que dada materialidade inclui ou exclui do seu conteúdo.

É o que a publicidade, de certa forma faz, segundo Souza Filho (2008), e cujo propósito primeiro seja o de persuadir e convencer o seu público a respeito de uma determinada ideia, produto ou serviço refletindo, para isso, a cultura da sociedade por meio de estratégias discursivas e intencionais como noções, conceitos e valores agregados aos produtos, em outras palavras, por meio de um regime enunciativo.

Daí a necessidade de criação de regimes de visibilidade (inclusive midiáticos) e uma ordem (enquadramento) do olhar que darão cadência aos desdobramentos significativos, pois, segundo Pollak (1989), o trabalho de enquadramento se constrói a partir do material fornecido pela história, assim, inevitavelmente, só entende determinada propaganda quem está conectado com essa ordem do olhar e com esse regime enunciativo. Logo, cabe ao nosso trabalho pensar um dado efeito estético como um operador de uma memória social.

\section{ANÁLISE DOS DADOS}

Tomando como base os preceitos da semiótica greimasiana, selecionamos como corpus para análise das categorias já mencionadas nesse estudo, um comercial da Rede Americana de Fast Food Burger King (doravante BK), a segunda maior rede de hambúrgueres do mundo, fundada em 1954, cuja missão “é ser a mais prazerosa experiência de alimentação”, bem como “a mais rentável e com foco no cliente”. Para atingir essa missão, o Burger King costuma abordar em suas campanhas publicitárias temas voltados à conscientização política, a favor da diversidade sexual, contra a discriminação racial e violências (de um modo geral), a exemplo das peças intituladas "Poliamor", "Saiba a diferença" e "Bullying", as quais traduzem, diante da sociedade, o posicionamento dessa rede de alimentação ao dizer que todos são bem-vindos, sem exceções.

Assim sendo, trouxemos um merchandising lançado, por essa rede de fast food, em janeiro de 2020 que 'brincou' com o programa de incentivo à abstinência sexual dos jovens defendido pela então ministra da Mulher, da Família e dos Direitos Humanos, Damares Alves, do governo Jair Bolsonaro. A campanha publicitária do BK lançou o "Combo Abstinência" o qual, segundo a marca, afirmava que era um combo feito para "quem quer sentir o prazer da carne, mas sem carne”. A promoção oferecia o Rebel Whopper, um sanduíche feito com 
hambúrguer à base de plantas, refrigerante e batata frita. Essa campanha, criada pela agência David, circularia pelas diversas mídias com um comercial em vídeo e, sobretudo, posts para as redes sociais, com a hashtag \#RelaxaeGosta ${ }^{7}$.

Figura 2. Entrevista da Damares sobre polêmica da abstinência sexual e projetos para 2020

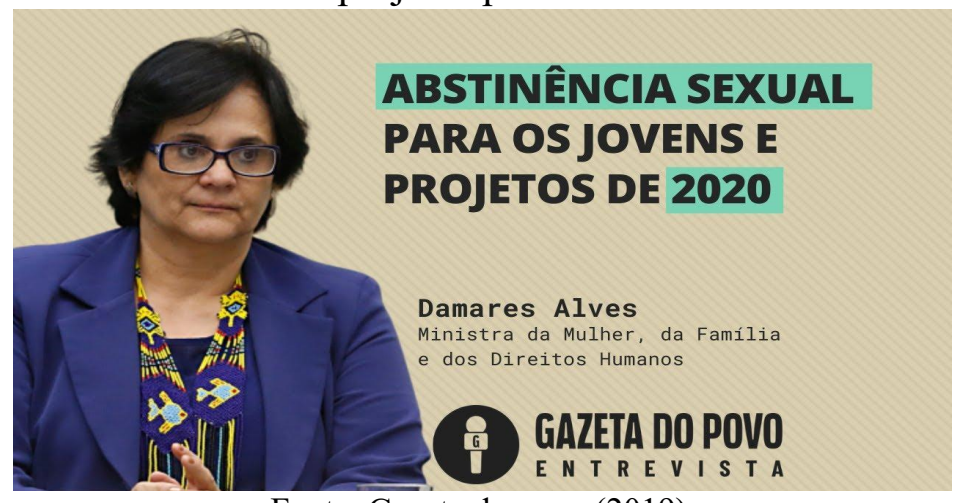

Fonte: Gazeta do povo (2019)

Figura 3. Burger King / Combo da abstinência

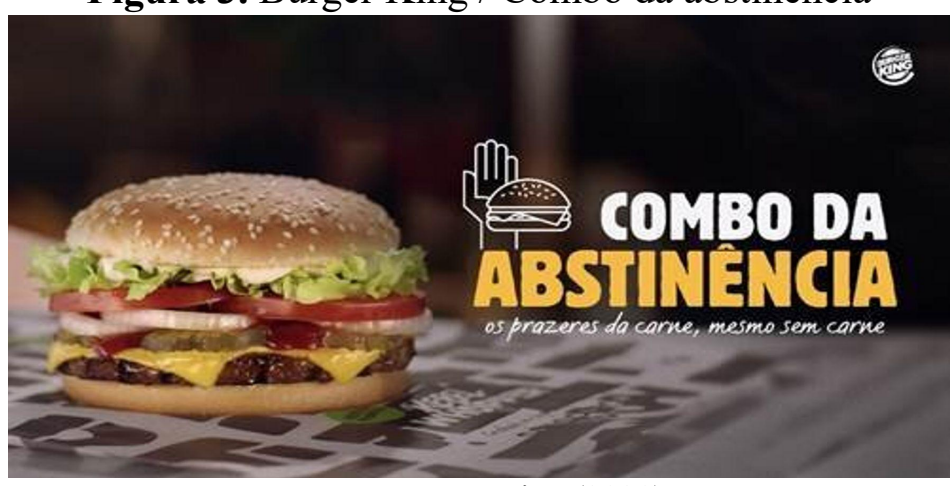

Fonte: Burger King (2020)

É evidente que a leitura das imagens anteriores, assim como de qualquer outro texto, nos permite identificar diferentes momentos, mas essa identificação se dará em diferentes níveis do conteúdo e do plano de expressão, conforme for a escolha de uso da linguagem no texto em questão. Desse modo, esta análise, baseando-se na teoria semiótica greimasiana, buscou desvelar a materialização de sentido na correlação de figuras e temas inerentes à campanha publicitária, citada acima, e empregar tal teoria ao texto que compõe o corpus de nossa análise por meio do Percurso Gerativo de Sentido e seus três níveis.

\subsection{NÍVEL FUNDAMENTAL}

\footnotetext{
${ }^{7}$ Baseada no "meme" da frase da senadora Marta Suplicy, que em 2007, quando era Ministra do Turismo, ao ser questionada sobre quais incentivos os brasileiros teriam para viajar, ela disse "relaxa e goza". Disponível em: http://g1.globo.com/Noticias/Politica/0,,MUL51536-5601,00.html. Acesso em: 16 mar. 2021.
} 
Como informado anteriormente, as estratégias do Burger King para atrair o público, assim como a divulgação dos seus produtos são, em grande maioria, pautadas na tentativa do bom humor, com propagandas criativas e irreverentes, muitas vezes polêmicas, sem medo de posicionar-se frente a diversas questões, principalmente as de cunho político e social. Dessa maneira, para a análise do nível fundamental, faz-se necessário determinar as categorias fundamentais que constroem o sentido mobilizado pela peça do BK intitulada "Combo da abstinência: os prazeres da carne, mesmo sem carne".

Nessa campanha, a categoria semântica fundamental é liberdade sexual vs privação sexual, dado que os termos 'liberdade' e 'privação' mantém um encadeamento de contrariedade e isso é explicitado de variadas formas no texto da campanha publicitária com os dizeres "Os prazeres da carne, mesmo sem carne", “0\% carne, $100 \%$ prazer", "evitar os prazeres da carne”, "abstinência", observe a Figura 4:

Figura 4. A oposição liberdade vs privação evidenciada pelas expressões usadas no comercial da Burger King/Combo da abstinência

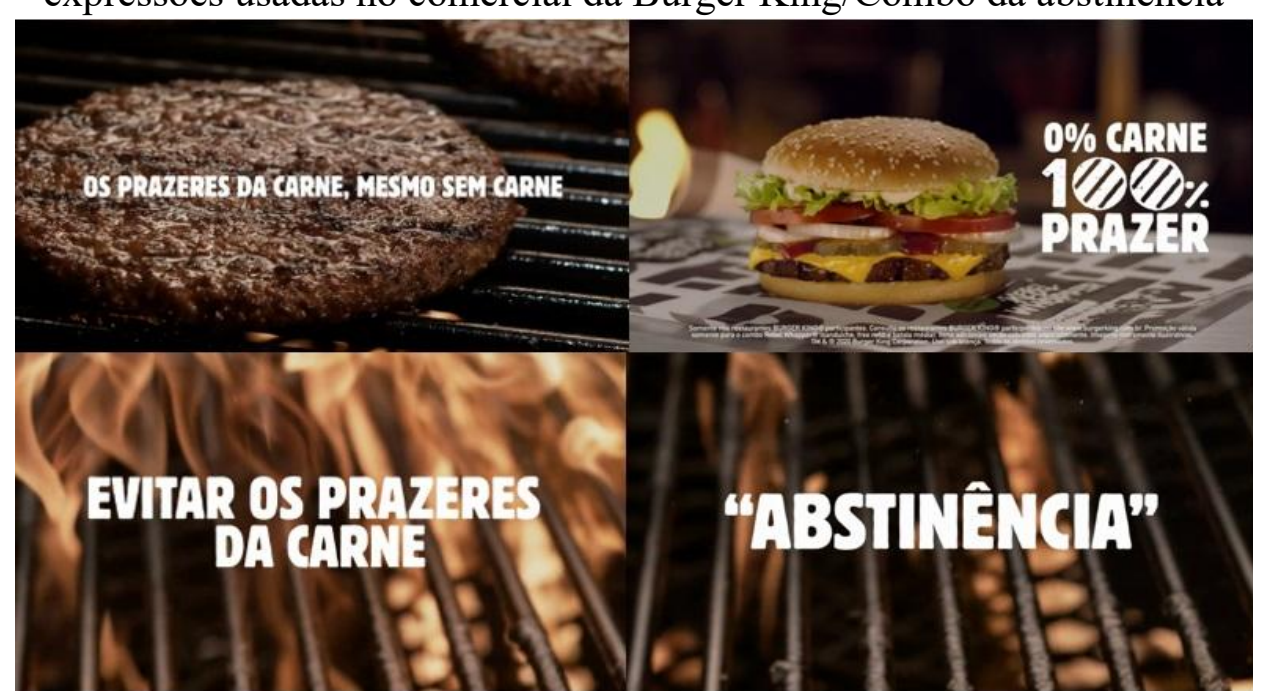

Fonte: Burger King (2020)

Além dos dizeres, a oposição semântica liberdade vs privação é reafirmada pela imagem de uma pequena mão que ora está aberta, que remete à privação, à não obtenção da carne, ora pegando o hambúrguer, representando a liberdade de poder pegar e comer a carne do sanduíche. O vídeo fica no formato de um bumerangue enquanto aparecem os textos, esse efeito faz com que a mão fique o tempo todo 'apalpando' o sanduíche, como observado na Figura 5: 
Figura 5 - A imagem da mão reafirmando a oposição semântica liberdade vs privação - Burger King/Combo da abstinência.

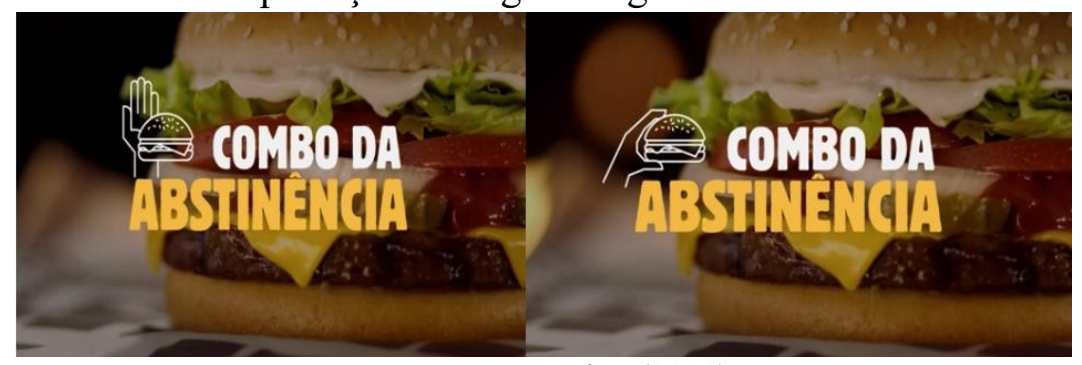

Fonte: Burger King (2020)

No corpus em análise, essa não-privação fica evidente na campanha por meio dos termos "aproveite enquanto dá" e "quem comeu, comeu", que instigam o público a aproveitar sua liberdade, observe na Figura 6:

Figura 6 - Burger King/Combo da abstinência.

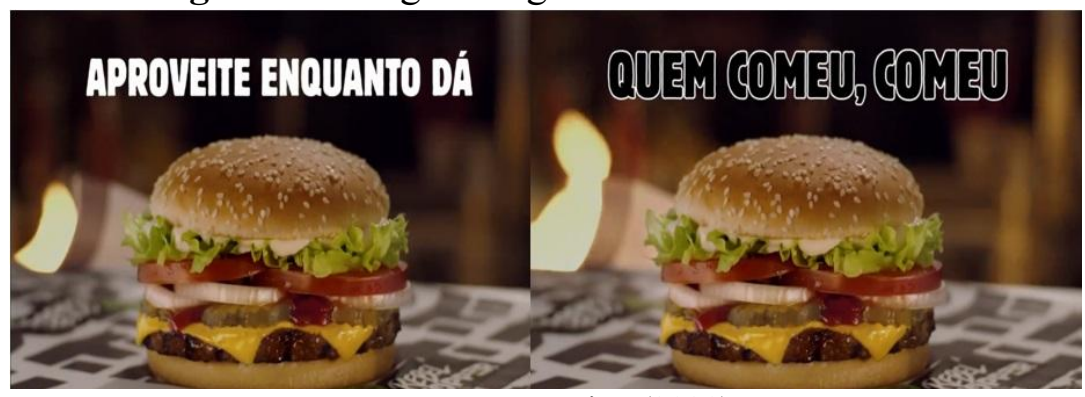

Fonte: Burger King (2020)

$\mathrm{Na}$ peça da BK, portanto, o conteúdo mínimo fundamental se dá pela negação da privação (tanto sexual quanto relacionada ao não consumo de carne), vista como negativa, e a afirmação da liberdade (sexual e gastronômica). Logo, em seu primeiro contato com a propaganda, será essa oposição que o público irá perceber, levando em consideração a construção dos elementos presentes na peça publicitária bem como o contexto no qual ela foi produzida - o período de divulgação da proposta da ministra Damares - que são fundamentais para a compreensão da mensagem transmitida pela rede de fast food.

\subsection{NÍVEL NARRATIVO}

Quanto a esse segundo nível do PGS, temos que as oposições semânticas, já estabelecidas, passam agora a assumir valores e circular entre sujeitos, isto é, de acordo com Morato (2008, p. 28), há uma "antropomorfização do conjunto lógico-conceitual” que é o aparecimento de um sujeito que assume a narrativa e acaba por estabelecer relações valorativas 
em objetos, portanto, deve-se determinar - no comercial da BK - os participantes e o papel que representam na narrativa para então verificar tais relações.

Sendo assim, temos, no corpus em questão, um destinador-manipulador a Rede de Fast Food BK e como destinatário-sujeito o público que ela quer atingir. Além disso, o objeto com o qual o destinatário mantém relação é o "combo da abstinência", um hambúrguer feito à base de plantas o qual é investido do valor "prazer, sedução". Para efetivar essa relação, tem-se um percurso de manipulação, no qual o destinador anuncia um "combo da abstinência", composto por $0 \%$ de carne, mas $100 \%$ de prazer, exibindo uma carne de hambúrguer grelhada e suculenta, com um fundo contendo a imagem (desfocada) de um fogo.

Tal exibição é ainda acompanhada por uma música 'sensual', a qual contribui para reafirmar esse valor dado ao objeto e, em um mesmo gesto interpretativo, reafirmar o discurso manipulador de sedução, direcionando, dessa forma, o destinatário a acreditar nessa valoração e consumir o hambúrguer para adquirir o valor almejado "os prazeres da carne, mesmo sem carne". Isto é, o destinatário passa a ceder à essa manipulação para desfrutar de $100 \%$ de prazer. Tanto é verdade que é usado a hashtag \#relaxaegosta a qual comprova o fazer-persuasivo do “combo da abstinência" em seduzir o público e, sobretudo, fazê-lo crer na satisfação da valoração a ser adquirida.

Figura 7. Comercial Burger King.

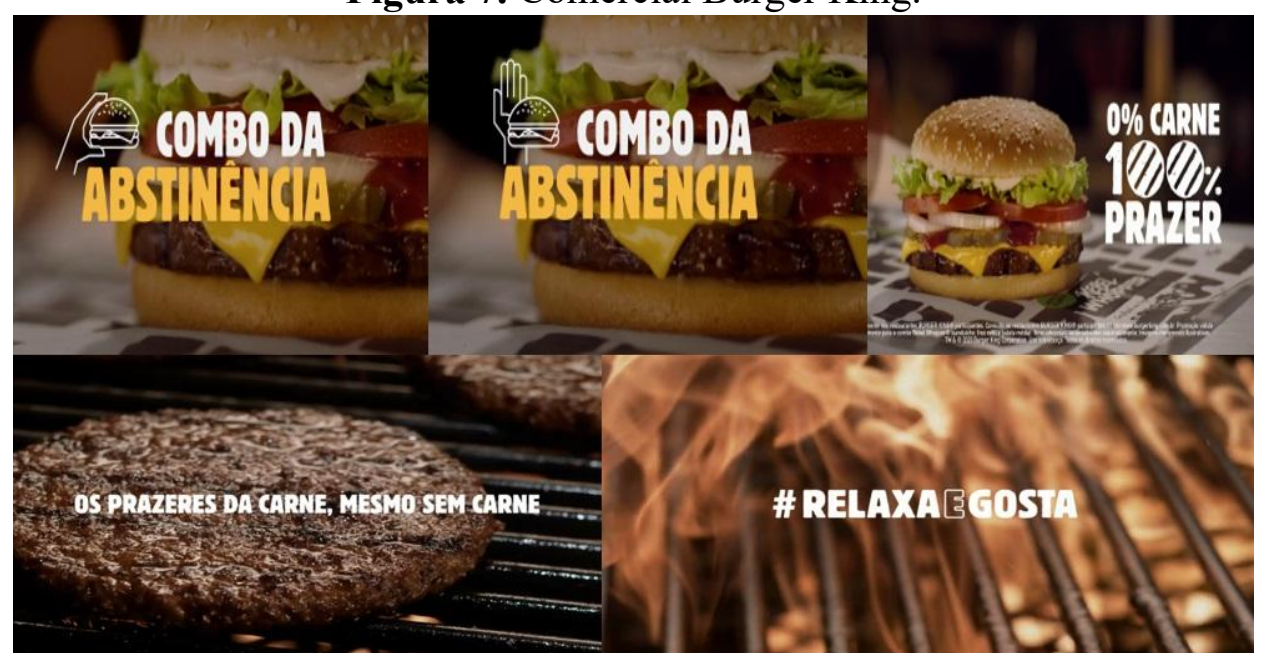

Fonte: Burger King (2020)

Além dessas estratégias usadas para a manipulação, cabe chamar atenção para a relação estabelecida entre a Rede de Fast Food e o programa de incentivo à abstinência sexual dos jovens, defendido pela ministra da 'Mulher, da Família e dos Direitos Humanos', Damares Alves a qual recebeu várias críticas devido à baixa ineficácia dos resultados e o alto custo do projeto lançado no mês de fevereiro de 2020. 
Figura 8. Comercial Burger King

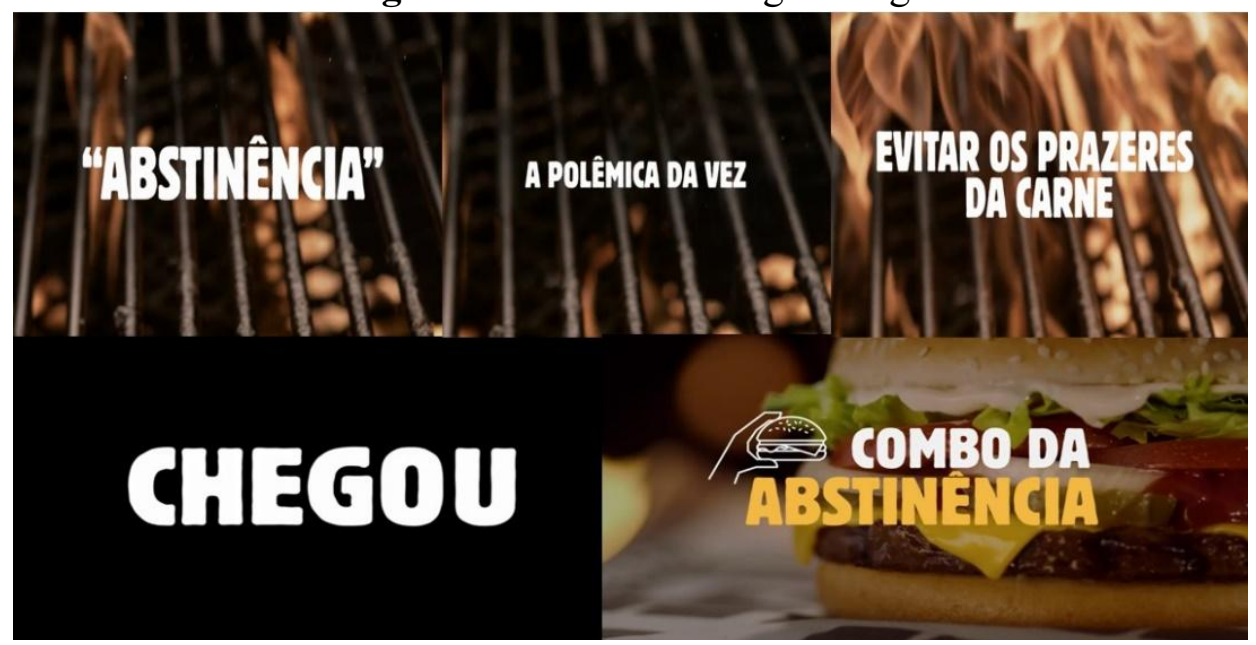

Fonte: Burger King (2020)

Sendo assim, por sempre abordar em suas campanhas temas de cunho político e social, a BK se aproveitou dessa "polêmica da vez"- sobre o projeto da ministra - e criou o "combo da abstinência", evidenciando uma dada formação ideológica a qual revela a ideia de neutralidade e imparcialidade das peças publicitárias, ou seja, há um direcionamento do olhar proporcionado pelo interlocutor-manipulador que veicula os valores defendidos por essa rede de Fast Food. Logo, a estruturação dessa materialidade discursiva conflui para uma memória coletiva midiatizada promovida pela $\mathrm{BK}$ que cria regimes de visibilidade possibilitando desdobramentos significativos, isto é, o "combo da abstinência" não é somente um produto a ser vendido, mas uma instância que mobiliza mais de uma interpretação a partir de um regime enunciativo, que é a própria construção da peça publicitária, dotada de duração e estabilidade.

Ainda no que diz respeito à dinâmica de enquadramento do olhar, a qual possibilita essa memória coletiva midiatizada, temos que considerar também as relações estabelecidas entre os sujeitos - nesse caso a BK e o respectivo público - como de suma importância para a apreensão dos sentidos estabelecidos pela estruturação da materialidade discursiva em questão. Então, vêse na peça publicitária da BK uma conjunção de elementos verbais, visuais e sonoros que, além de ajudar a formar a interpretação global do texto, servirá como um método de persuasão do leitor para levá-lo à aquisição do seu produto ou à aceitação de uma ideia, ou seja, a novos enquadramentos.

\subsection{NÍVEL DISCURSIVO}

Último nível do PGS, é o mais próximo da manifestação textual "real" e onde ocorre a solidificação discursiva do nível narrativo. É o lugar em que acontece também a conversão dos 
percursos narrativos em percursos temáticos, revestidos por figuras que representam o mundo em que o discurso - da propaganda do $B K$ - está inserido.

É importante destacar que toda peça publicitária lança mão de diversos recursos na sua composição com o intuito de a tornar mais atrativa, intensificar a mensagem e destacar o produto que pretende promover e, com a propaganda em questão do $\mathrm{BK}$, não é diferente. Ao assistir ao vídeo publicitário, podemos perceber o uso de diversos intensificadores do discurso - recursos usados para, como o próprio nome sugere, intensificar o discurso proferido -, tais como: efeito sonoro, ao fundo a presença do fogo, cadeias enunciativas do tempo e a proposição verbal.

O primeiro elemento que se nota é a trilha sonora. A propaganda utiliza uma música instrumental envolvente, com notas sensuais, rica em nuances que inicia com lentas batidas e acelera à medida que o vídeo avança e as informações aparecerem, envolvendo o leitor de maneira sensual, "quente" (fogo) e provocante, reforçando o teor sexual proposto pela peça publicitária, que vai de encontro ao projeto de abstinência proposto pela ministra Damares.

Figura 9 - Imagem do fundo da propaganda 'Combo da abstinência'/Burger King

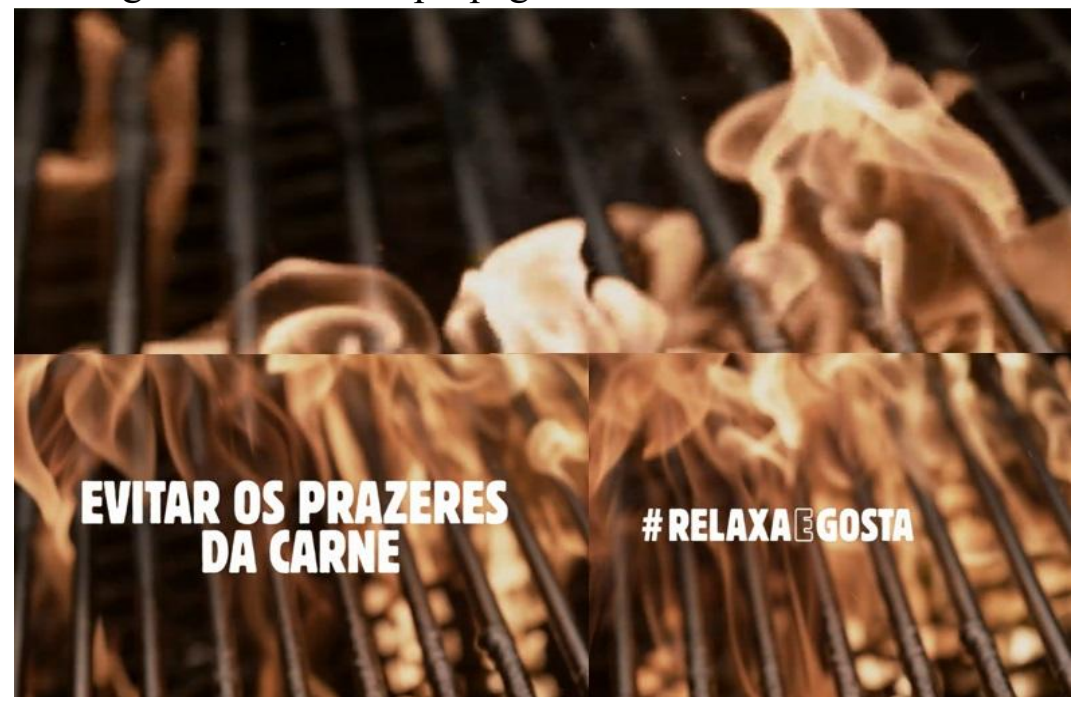

Fonte: Burger King (2020)

A presença do fogo contribui para a construção da atmosfera erotizada, assim como pode fazer referência ao 'calor' relacionado à excitação, quando combinado com a música sensual, despertam o desejo do público, tanto para o sexual quanto para o consumo da carne que aparece a todo momento na grelha, em contato com o fogo.

O uso de tal intensificador discursivo prende a atenção do espectador causando-lhe um impacto que, de imediato, associa as proposições verbais a um discurso sensual. Nessa propaganda, os dados principais que sustentam a argumentação são as expressões intensificadas 


\section{Linguagens - Revista de Letras, Artes e Comunicação - ISSN 1981- 9943 \\ Blumenau, v. 14, n. 2, p. 143-163, maio/ago. 2020. \\ DOI: http://dx.doi.org/10.7867/1981-9943.2020v14n2p143-163}

pelo uso dos verbos que se apresentam nos seguintes exemplos: 'aproveite enquanto dá', '\#relaxa e gosta' e 'quem comeu, comeu'. A presença desses verbos reforça, na ordem do olhar estabelecida, a impressão sexual sugerida pela peça publicitária, contribuindo de uma forma significativa para a construção isotópica no sentido do texto. No entanto, a ideia erótica é desfeita ao atentarmos para a imagem do hambúrguer, posto em destaque, salientando uma segunda interpretação ao que a propaganda se refere.

Com isso podemos notar que o BK, de forma satisfatória, consegue capturar a atenção do público ao produzir uma propaganda em que associa seu produto à questão sexual, ao mesmo tempo que ironiza a proposta da ministra Damares - situando a audiência no contexto da peça produzida -, fazendo com que o indivíduo fique tentado a provar o Rebel Whopper e sinta-se parte do grupo de pessoas que vai de encontro à essa proposta e não querem "abrir mão dos prazeres da carne", optando assim por outro tipo de carne.

\section{OUTRAS PALAVRAS: OS PLANOS DE LEITURA EM EVIDÊNCIA}

Considerando as categorias já analisadas e o que anunciamos como objetivo geral, evidenciando relações ideológicas entre interlocutores, cabe agora discorrermos, enquanto rito interpretativo final, sobre as relações figurativas e temáticas que contribuem para aquilo que os estudos semióticos procuram hoje determinar: o que o texto diz, como o diz e para o que o faz. Afinal, faz-se necessário estabelecer as relações isotópicas que se constituem no texto em análise, explanando os sentidos formados por essas relações, corroborando para que a peça publicitária, em questão, circule em um dado contexto sócio histórico.

Destarte, destacamos os significados que os elementos visuais e verbais, citados nos tópicos anteriores, transportam aos seus enunciatários. Nessa percepção, podemos identificar, no vídeo, várias isotopias intercaladas ao texto, as quais contribuem para a interpretação, convergindo com o propósito da propaganda. Logo, é possível identificar os termos isotópicos apresentados no Quadro 1 a seguir. 
Quadro 1: Termos Isotópicos na Propaganda do BK

\begin{tabular}{|c|c|c|c|}
\hline \multicolumn{4}{|c|}{ TERMOS ISOTÓPICOS NA PROPAGANDA DO BK } \\
\hline \multicolumn{2}{|c|}{ ABSTINÊNCIA } & \multicolumn{2}{|c|}{ CARNE } \\
\hline Falta de sexo & Falta da carne & Corpo & Alimento \\
\hline \multicolumn{2}{|c|}{ COMEU } & \multicolumn{2}{|c|}{ PRAZER } \\
\hline Praticou o ato sexual & Consumiu carne & Sexual & Gastronômico \\
\hline \multicolumn{2}{|c|}{ APROVEITE ENQUANTO DÁ } & \multicolumn{2}{|c|}{ DESENHO DA MÃO } \\
\hline $\begin{array}{c}\text { Aproveitar o ato } \\
\text { sexual }\end{array}$ & $\begin{array}{c}\text { Aproveitar o } \\
\text { consumo da carne }\end{array}$ & $\begin{array}{l}\text { Apalpar al } \\
\text { sexualmen }\end{array}$ & Pegar o sanduíche \\
\hline
\end{tabular}

Fonte: Nossa autoria.

Explanando os termos apresentados, podemos perceber que a expressão 'Abstinência' que faz alusão tanto para o discurso emitido pela atual ministra Damares Alves, quanto para a abstenção do consumo da carne de origem animal. Similar à esta, outras isotopias podem ser observadas na sequência, como o termo "carne" em "evitar os prazeres da carne", o qual pode se referir à carne corporal ou à carne alimento; temos também o verbo "comeu" na oração "quem comeu, comeu", o qual ora dá ideia de comer o "combo da abstinência" ora tem um sentido pejorativo para significar que alguém já se relacionou sexualmente com outrem.

Esse fenômeno da isotopia está presente também na expressão "aproveite enquanto dá" que pode significar a ideia de aproveitar enquanto consome o "combo da abstinência" ou aproveitar o momento do ato sexual. Além disso, temos a expressão isotópica "prazer" em “ $100 \%$ prazer” que evidencia o prazer gastronômico ou o prazer sexual. Porém, não são só as expressões verbais que fortalecem essa semântica textual da BK. Temos o desenho da mão que ora está levantada, ora pegando o hambúrguer, o que isotopicamente significa apalpar sexualmente ou pegar o hambúrguer literalmente. Todos esses traços semânticos expostos ao longo do discurso contribuem para reafirmar a coerência textual proporcionando um plano de leitura, isto é, determinando ao público um modo de ler o texto.

Nessa perspectiva, para entender a propaganda elaborada pela BK, o público deve, por meio de inferências textuais e intertextuais já aqui mencionadas, realizar a desambiguação dos termos isotópicos, propiciando o real sentido das palavras, no contexto, o qual advém das relações que esse público-alvo estabelece com o sistema social em geral. E todo esse 
encadeamento converge, portanto, de forma direta, para promover o alcance de uma dada memória por outra perspectiva, a qual é constituída, de acordo com Pollak (1992), por acontecimentos, pessoas e lugares conhecidos de uma forma ou de outra pelo indivíduo (ou pelo grupo a que ele pertence), possibilitando a lembrança e, consequentemente, o entendimento da materialidade textual que acaba por ser estável e durável no tempo e no espaço.

\section{CONSIDERAÇÕES FINAIS}

Portanto, o desenvolvimento do presente artigo possibilitou uma análise sobre as múltiplas formas de estratégias textuais isotópicas, utilizadas pela publicidade investigada, com o intuito de atingir um determinado público; a articulação temática e figurativa dos elementos verbais e visuais evidenciaram as relações ideológicas entre o público-alvo e o sistema social e, reafirmaram que o texto não somente diz algo, mas cria formas para dizer o que exatamente deseja. De modo geral, a propaganda em questão apresenta múltiplos significados, o que facilitou a busca por resultados que deixassem em evidência os objetivos específicos pretendidos para este trabalho, ou seja, apresentar os modos de articulação na publicidade - a materialização de sentido entre temas e figuras - que foram apurados por meio do PGS e seus três níveis designando, assim, o universo semântico e os mecanismos verbais e visuais, que se inter-relacionam na propaganda em questão.

Dada à importância do tema, no que concerne a noção de isotopia conectada à Análise do Discurso, a pesquisa realizada pôde mostrar, através da interpretação do texto sincrético presente no gênero publicidade, que um texto isotópico pode estar repleto de combinações de sentido o qual se dá por meio da interação entre leitor e texto. Nesse sentido, acreditamos que se faz necessário empreender análises, como as operacionalizadas nesse artigo, para o estudo com o texto em sala de aula, já que é possível ampliar a competência leitora dos alunos contribuindo para a melhoria no processo de ensino-aprendizagem. Além disso, o trabalho com o gênero publicidade pode ser um artifício para proceder o estudo dos modos de produzir efeitos de sentido, visto que, nesse gênero discursivo se observa a recorrência de temas e figuras que se materializam possibilitando uma ordem do olhar ao leitor.

\section{REFERÊNCIAS}

BARROS, Diana Luz Pessoa de. Teoria semiótica do texto. São Paulo: Ática, 2005. 
CRESTANI, Luciana Maria; CAYSER, Elisane Regina; SANTOS, João Ricardo Fagundes dos. O sincretismo na publicidade social: a construção solidária de sentidos. Linguagem e Ensino, Pelotas, v. 22, n. 1, p. 294.

FIORIN, José Luiz. Sendas e veredas da semiótica narrativa e discursiva. DELTA, São Paulo, v. 15, n. 1, p. 00, Feb. 1999. Disponível em: Sendas e veredas da semiótica narrativa e discursiva.http://www.scielo.br/scielo.php?script=sci_arttext\&pid=S010244501999000100009\&lng=en\&nrm=iso. Acesso em: 16 fev. 2020.

GREIMAS, A. J.; COURTÉS, J. Dicionário de semiótica. São Paulo: Cultrix, 1979.

HOLANDA, Aurélio Buarque de. Novo dicionário de língua portuguesa. Rio de Janeiro: Nova Fronteira, 1986.

HENN, R. C. Processos intersemióticos na semiosfera midiatizada. In: Luci Teixeira. (Org.). Linguagens: estudos interdisciplinares e multiculturais. Estudos intersemióticos. 1ed. Belém: Universidade da Amazônia, 2006, v. 3, p. 223-241.

KING, Burger. Combo da Abstinência. 2020. (0m29s). Disponível em: https://www.youtube.com/watch?v=vhePMD38Suw. Acesso em: 24 mar. 2020.

LEITE, Ricardo Lopes. Isotopia e metaforização textual. Niterói, n 26, p. 121-134, 2009.

LEITE, Ricardo Lopes. Isotopia e metaforização textual. In: PELOSI, A. C.; FELTES, H. P. D. M.; FARIAS, E. M. P. (org.). Cognição e Linguística: explorando territórios, mapeamentos e percursos. 2. ed. Caxias do Sul - RS: Educs, 2014. p: 122.

LORENZ, R. A noção de isotopia: uma aliada na leitura do texto poético. $12^{\circ}$ Seminário Internacional de Pesquisa em Leitura e Patrimônio Cultural Leitura, arte e patrimônio: redesenhando redes. $15^{\circ}$ Jornada Nacional de Literatura: Leituras jovens do mundo. Passo Fundo: UPF. 2013. p. 1.

MORATO, Elisson Ferreira. Do conteúdo à expressão: uma análise semiótica dos textos pictórios de mestre Ataíde. Dissertação (Mestrado - Programa de Pós-Graduação em Estudos Linguísticos) - Faculdade de Letras da Universidade Federal de Minas Gerais, Belo Horizonte, 2008.

NÓBREGA, Fernando Antônio Azevedo. Desambiguação lexical de sentidos para o português por meio de uma abordagem multilíngue mono e multidocumento. Dissertação (Mestrado - Programa de Pós-Graduação em Ciências de Computação e Matemática Computacional) - Instituto de Ciências Matemáticas e de Computação, Universidade de São Paulo. São Carlos, 2013.

POVO, Gazeta do. ENTREVISTA Damares fala sobre polêmica da abstinência sexual e projetos de 2020. 2019 (42m01s). Disponível em: https://www.youtube.com/watch?v=pKQh995n3dY\&t=1s. Acesso em: 24 mar. 2019.

POLLAK, M. Memória e identidade social. Estudos Históricos, Rio de Janeiro, v. 5, n. 10, p. 200-212, 1992. 
POLLAK, M. Memória, esquecimento, silêncio. Estudos Históricos. Rio de Janeiro, v. 2, n. 3, p. 3-15, 1989.

RIESS, A. B.; GABRIEL, R. A desambiguação lexical durante a compreensão leitora em inglês como língua estrangeira. Letras de Hoje, Santa Cruz do Sul, RS, Brasil, v. 54, n. 2, p. 181-190, Jun 2019. Disponível em: http://dx.doi.org/10.15448/1984-7726.2019.2. Acesso em: 19 fev. 2020.

SILVA, V. S. D. S. Desambiguação automática de substantivos em corpus do português brasileiro. Dissertação (Mestrado) - Faculdade de Filosofia, Letras e Ciências Humanas da Universidade de São Paulo. São Paulo, 2016.

SOUZA FILHO, Erasmo Borges de. "Chronos" - A semiótica que não pára no texto. In: Luci Teixeira. (Org.). Linguagens II: Estudos Interdisciplinares e Multiculturais. Estudos Intersemióticos. Belém: Editora Unama, 2008. v. 3. p. 23-37. 